\title{
Mesenchymal stem cells and carcinoma-associated fibroblasts sensitize breast cancer cells in 3D cultures to kinase inhibitors
}

\author{
ANGELA DITTMER $^{1}$, ALEXANDER FUCHS ${ }^{2}$, ILKA OERLECKE $^{1}$, BENJAMIN LEYH $^{1}$, SUSANN KAISER $^{2}$, \\ JOHN W.M. MARTENS ${ }^{3}$, JANA LÜTZKENDORF ${ }^{4}$, LUTZ MÜLLER ${ }^{4}$ and JÜRGEN DITTMER ${ }^{1}$ \\ ${ }^{1}$ Klinik für Gynäkologie, Universität Halle; ${ }^{2}$ Novartis Pharma GmbH, Oncology, Nürnberg, Germany; \\ ${ }^{3}$ Department of Medical Oncology, Erasmus University Medical Center, Rotterdam, The Netherlands; \\ ${ }^{4}$ Zentrum für Innere Medizin, Klinik für Innere Medizin IV, Universität Halle, Germany
}

Received March 21, 2011; Accepted May 3, 2011

DOI: $10.3892 /$ ijo.2011.1073

\begin{abstract}
Stromal cells, such as mesenchymal stem cells (MSCs) and carcinoma-associated fibroblasts (CAFs), play a role in cancer progression. To analyze their ability to modulate drug response, we generated spheroids of MCF-7 or MDA-MB-231 breast cancer cells in the absence or presence of human (h)MSCs or hCAFs and tested the susceptibility of the breast cancer cells to three different kinase inhibitors (TKI258, RAD001 and RAF265) used in cancer therapy. While stromal cells did not affect the response of either breast cancer cell line to the PDGFR/FGFR/VEGFR inhibitor TKI258, they sensitized breast cancer cells to the mTOR inhibitor RAD001. In MCF-7 cells, this was accompanied by increased apoptosis. hMSCs and to a lesser extent hCAFs also enhanced the cytotoxic effect of RAF inhibitor RAF265 on MDA-MB-231 cells. Searching for the mechanism that underlies the effect of stromal cells on RAF265 response we found that stromal cells inhibited RAF265-induced increase in ERK1/2 phosphorylation, supported RAF265-dependent downregulation of PKC $\alpha$ (protein kinase $\mathrm{C} \alpha$ ) and prevented RAF265-induced conversion of LC3B, a marker of autophagy. To mimic the changes in ERK1/2 phosphorylation and PKC $\alpha$ expression in response to the stromal cells, we treated cells with MEK1 inhibitor U0126 or PKCa inhibitor Gö6976, respectively. U0126, but not Gö6976, was as effective as hMSCs in sensitizing MDA-MB-231 cells to RAF265. This suggests that hMSCs and hCAFs increased the cytotoxic effect of RAF265 on MDA-MB-231 cells by downregulating ERK1/2 phosphorylation. In summary, this study shows that hMSCs are able to render breast cancer cells more susceptible to kinase inhibitors and that, to the most part, hCAFs to which hMSCs can differentiate are able to mimic the drug-sensitizing effects of hMSCs.
\end{abstract}

Correspondence to: Dr Jürgen Dittmer, Klinik für Gynäkologie, Universität Halle, Ernst-Grube-Str. 40, D-06120 Halle/Saale, Germany E-mail: juergen.dittmer@medizin.uni-halle.de

Key words: MSCs, CAFs, Raf inhibitor, breast cancer, ERK1/2, Ets1

\section{Introduction}

Tumor-associated stromal cells, such as carcinoma-associated fibroblasts (CAFs), have been shown to promote tumor progression (1-4). Recently, also mesenchymal stem cells (MSCs) have been reported to modulate tumor behavior (5-7). MSCs are multipotent stem cells that derive from the bone. The minimal criteria that are used to define this type of cell are the expression of CD105, CD73 and CD90, the lack of CD45, CD14 and CD35, the abilitity to differentiate to adipocytes, chondrocytes and osteoblasts and to adhere to plastic surfaces (8). Playing a role in wound repair, MSCs enter injured tissues (7), where they reduce inflammation (9), enhance bacterial clearance (10) and may differentiate to cells that help the tissue to be restored (11). Solid tumors, probably mistaken by MSCs as wounds, also attract MSCs leading to interactions between MSCs and tumor cells (12-15). Depending on the conditions and the type of tumor, MSCs have been shown to negatively or positively affect tumor progression (5-7). MSCs might also have an influence on drug response, as it has been shown that MSCs can differentiate to CAFs $(16,17)$ which are able to protect tumor cells against anti-VEGF treatment (18). Likewise, endothelial cells that are able to convert to MSCs (19) can form a chemo-resistant niche for lymphoma cells (20).

The Ras/Raf/MEK/ERK1/2 and the PI3K/AKT/mTOR pathways are often deregulated in cancer and promote cell proliferation and survival. Both pathways can be stimulated by receptor tyrosine kinases (RTKs) (21). In breast cancer, depending on the subtype (22-24), Her2, EGFR and/or FGFR are the major RTKs that are responsible for the activation of these pathways $(25,26)$. Inhibition of the RTKs are among the routinely used strategies to treat patients with breast cancer (27). Alternatively, drugs may be used that directly target components of the Ras/Raf/MEK/ERK1/2 and the PI3K/AKT/ mTOR pathways (28-30). Blockage of these pathways, e.g., by RAF or mTOR inhibitors, has been demonstrated to induce cancer cell death (30-32). Direct inhibition of these pathways may be of particular importance when breast cancers develop resistance to the RTK inhibitor (33).

We sought to analyze whether hMSCs and hCAFs have an impact on the responses of breast cancer cells to inhibitors of 
Ras/Raf/MEK/ERK1/2 and PI3K/AKT/mTOR pathways. To mimic more closely the function of living tissue we used threedimensional (3D) cultures (34). We have previously shown that 3D-cultured MCF-7 breast cancer cells form spheroids which attract hMSCs (15). After invading the spheroid hMSCs disturbed its architecture by interfering with E-cadherindependent cell-cell adhesion. hMSCs are also able to enter 3D cell aggregates of mesenchymal-type MDA-MB-231 breast cancer cells that do not form well-organized spheroids. We show here, that hMSCs and/or hCAFs sensitize 3D-grown MCF-7 and MDA-MB-231 cells to mTOR inhibitor RAD001. In addition, these stromal cells also increase the response of MDA-MB-231 cells to the RAF inhibitor RAF265.

\section{Materials and methods}

Cell culture. MDA-MB-231 cells, MCF-7 cells and 19TT-hCAFs (35) were grown in Glutamax-containing RPMI (Invitrogen) and $10 \%$ fetal calf serum (PAN) in the absence of antibiotics. hMSCs were isolated and propagated as described (15). All cells were grown and treated in the same batch of serum. Cells were cultured in 3D as described (36).

Generation of homotypic and heterotypic breast cancer spheroids. For the generation of 3-day-old heterotypic spheroids, trypsinized hCAFs or hMSCs were mixed with trypsinized breast cancer cells at a ratio of 1:500 and grown in 3D cultures for 3 days. To produce 4-day-old heterotypic spheroids, trypsinized hCAFs were incubated with 3-day-old spheroids at an approximate ratio of 1:5 (hCAFs/breast cancer cells) for 1 day.

Treatment with kinase inhibitors. Kinase inhibitors RAF265 (Novartis), RAD001 (Novartis), TKI258 (Novartis), Gö6976 (Calbiochem) and U0126 (Calbiochem) were dissolved in DMSO and added to cells at a final concentration of 1,2 or $10 \mu \mathrm{M}$. Mock treatment was performed by adding the equivalent amount of DMSO. In 2D cultures, drugs were administered to cells $2 \mathrm{~h}$ after trypsinization when cells were completely attached. In 3D cultures, inhibitors were added to 3-day-old homotypic or 3-day-old or 4-day-old heterotypic spheroids.

Immunocytochemistry. Immunocytochemistry analysis of formaldehyde-fixed and paraffin-embedded 3D cell aggregates was performed as described (36). Anti-vimentin (mouse monoclonal, Dako, clone V9) was used at a dilution of 1:400.

Viability assay. Viability was determined by using a luciferase-based ATP assay kit (ViaLight Plus Kit, Lonza). Plastic-adherent cells grown in $25 \mathrm{~cm}^{2}$ flasks were washed with PBS and lysed at RT by adding $400 \mu \mathrm{l}$ of lysis buffer on top of the cell layer. Cell lysates were then transferred to microfuges and cleared by centrifugation at $4000 \mathrm{rpm}$ for $5 \mathrm{~min}$. Cells in 3D cultures were pelleted at $4000 \mathrm{rpm}$ for 5 min, washed once with PBS and lysed by incubation in $400 \mu \mathrm{l}$ lysis buffer at RT for $10 \mathrm{~min}$. Clearance of the lysates was performed as described above. Cleared lysates were used for ATP measurement as follows. Cleared lysate $(10 \mu \mathrm{l})$ was mixed with $45 \mu 1$ lysis buffer and $100 \mu 1$ luciferase stock solu-

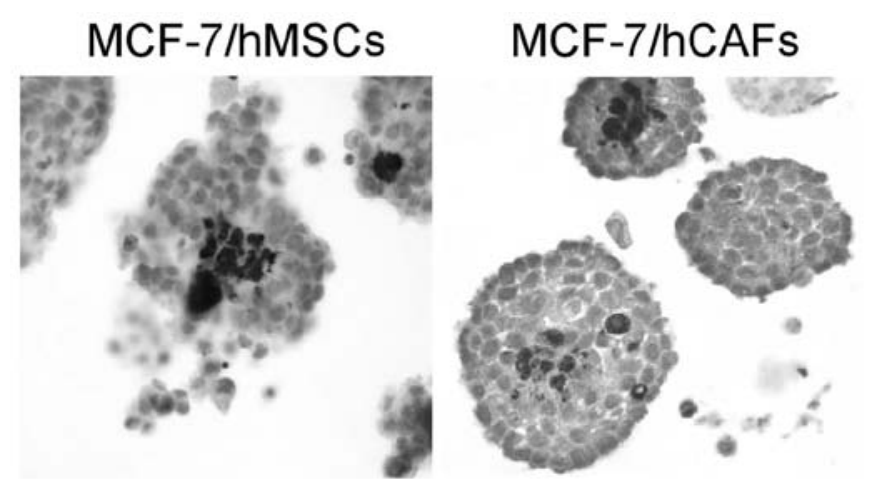

Figure 1. hMSCs and hCAFs form heterotypic spheroids with breast cancer cells. MCF-7 cells were mixed either with hCAFs or hMSCs in a ratio of 500:1 and grown in 3D cultures for 3 days. Spheroids were formalin-fixed and paraffin-embedded for immunocytochemistry. hCAFs and hMSCs were selectively visualized by using an antibody against vimentin.

tion. Luminescence was measured in a Sirius luminometer (Berholt). Relative cell viability was calculated by dividing the relative light units (RLUs) as obtained for a given sample by the RLUs of the corresponding control. Concentrations of total protein in the extracts were measured by using the Pierce BCA protein assay kit.

Western blot analysis and RNA interference. Western blot analysis was carried out as described (37) by using antibodies against the 25-kDa-PARP-1 fragment (rabbit monoclonal, 1:10,000, Epitomics), anti-E-cadherin (BD Transduction Lab, mouse monoclonal, clone 36, 1:10,000), anti-Ets1 (rabbit polyclonal, C20, 1:2,000, Santa Cruz), anti-phospho-Thr-38 Ets1 (rabbit polyclonal, 1:1,000, Acris), anti-PKC $\alpha$ (rabbit polyclonal, 1:2,000, Santa Cruz), anti-LC3B (rabbit polyclonal, 1:1,000, Cell Signaling Technology), anti-GAPDH (rabbit monoclonal, 1:5,000, Epitomics), anti-phospho-Thr202/ Tyr204-ERK1/2 (rabbit polyclonal, 1:2,000, Cell Signaling Technology) or anti-ERK1/2 (rabbit polyclonal, 1:2,000, Cell Signaling Technology). For detection an anti-mouse or anti-rabbit horseradish peroxidise conjugate $(1: 2,000$, New England Biolabs) was used.

For RNA interference, MCF-7 cells were transfected with a PKC $\alpha$-specific siRNA (siP $\alpha$ ) or a control siRNA (siLuc) (38) and grown in 3D culture for four days as described (36).

\section{Results}

hMSCs and hCAFs form heterotypic spheroids with breast cancer cells. To study the effect of hMSCs and hCAFs on drug-treated breast cancer cells in 3D cultures, we generated heterotypic, stromal cell-containing and homotypic breast cancer cell spheroids as described in Materials and methods. First we confirmed that heterotypic tumor spheroids contain stromal cells. Heterotypic and homotypic MCF-7 spheroids were fixed, paraffin-embedded, and sectioned for immunocytochemistry. Stromal cells were visualized by using an antibody against vimentin, a marker for mesenchymal cells (15). As shown in Fig. 1, vimentin-positive cells could be detected in heterotypic spheroids formed by MCF-7 cells in 
MCF-7

MDA-MB-231

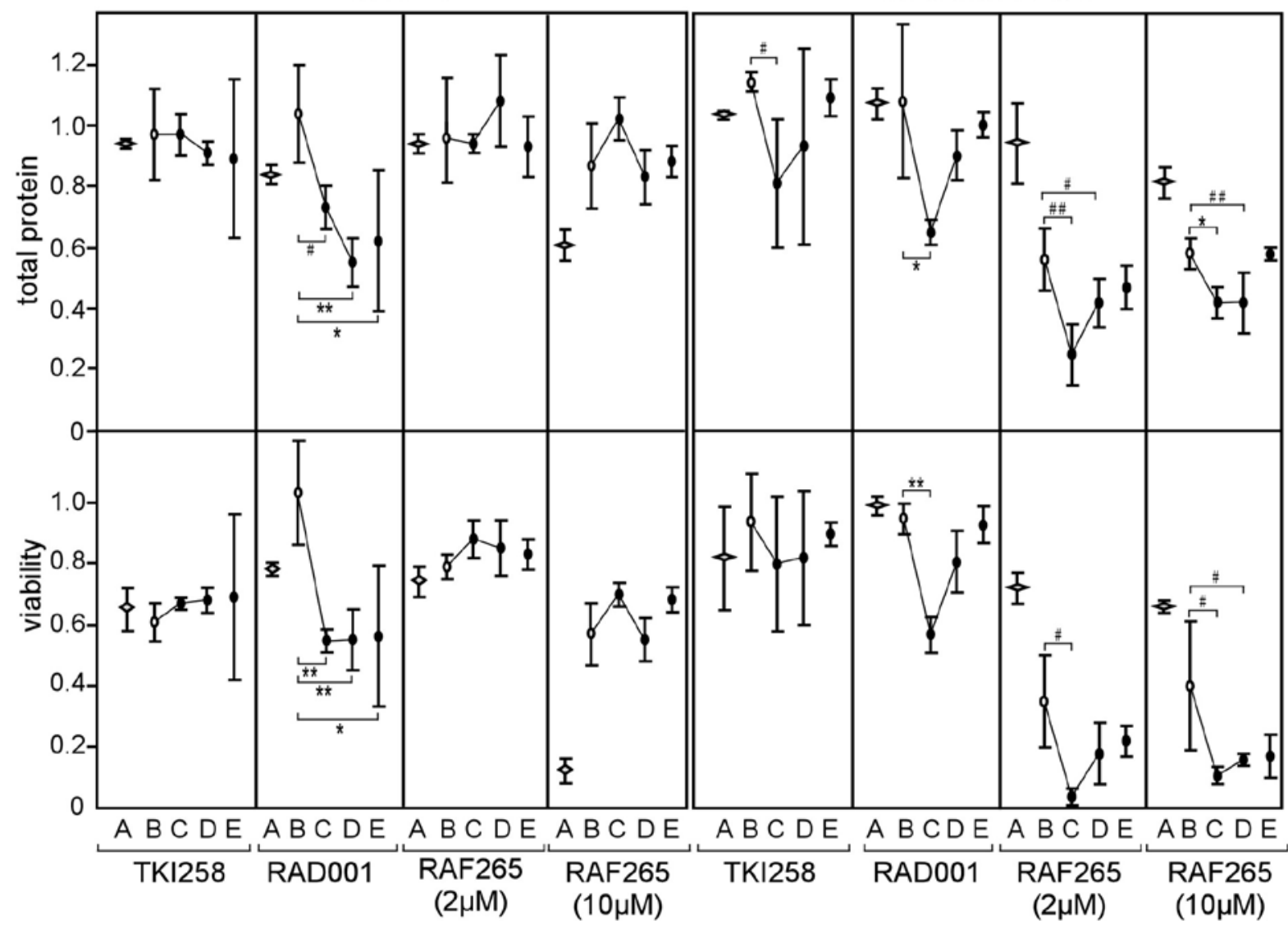

Figure 2. hMSCs sensitize breast cancer cells to RAF265 and RAD001. MCF-7 or MDA-MB-231 cells were either grown in 2D or 3D cultures and incubated under various conditions $(\mathrm{A}=2 \mathrm{D}, \mathrm{B}=3 \mathrm{D}$, no stromal cells, $\mathrm{C}=3 \mathrm{D}+\mathrm{hMSCs}$ added on day $0, \mathrm{D}=3 \mathrm{D}+\mathrm{hCAFs}$ added on day 0 , $\mathrm{E}=3 \mathrm{D}+\mathrm{hCAFs}$ added on day 3). In 3D cultures, kinase inhibitors or solvent without inhibitor (mock) were either added on day 3 of culturing (B-D) or on day 4 (E). Cells were then drug- or mock-treated for 3 days before they were lysed for measuring cell viability and total protein content. Each value was calculated by dividing the value as found in the presence of the drug by the value obtained with the corresponding mock-treated control. Each dot represents the average value ( \pm SD) of 3-9 independent experiments. Statistical significance was determined by the student t-test $\left.{ }^{(\#} \mathrm{p}<0.05,{ }^{\# \#} \mathrm{p}<0.01,{ }^{*} \mathrm{p}<0.005,{ }^{* * *} \mathrm{p}<0.001\right)$.

the presence of hMSCs or hCAFs, but not in control homotypic MCF-7 spheroids (data not shown).

hMSCs and hCAFs sensitize breast cancer cells to RAD001 and RAF265 in 3D cultures. Next we examined the effects of kinase inhibitors (mTOR inhibitor RAD001, RAF inhibitor RAF265 and PDGFR/FGFR/VEGFR inhibitor TKI2589) on the viability on MCF-7 and MDA-MB-231 cells in homotypic and heterotypic spheroids. For comparison, we also tested the effects of these inhibitors on cells grown in conventional 2D adherent cultures. Tumor spheroids and monolayers were exposed to the drugs for three days before cells were lysed for measurement of intracellular ATP (viability) and total protein content.

TKI258 reduced viability of MCF-7 cells at $10 \mu \mathrm{M}$ by $30-40 \%$ and that of MDA-MB-231 cells by $20 \%$ (Fig. 2). Total protein content was only weakly affected. No effect of stromal cells on the response of breast cancer cells to TKI258 was observed. Since TKI258 targets receptor tyrosine kinases which have the potential to stimulate the RAS/RAF/MEK1/ ERK1/2 pathway, we also analyzed the ERK1/2 phosphorylation status. We found that, in MDA-MB-231 cells, ERK1/2 phosphorylation was unaffected by TKI258 (Fig. 4A) whereas, in MCF-7 cells, TKI258 induced an increase in ERK1/2 phosphorylation (Fig. 3A). Hence, TKI258 did not reduce ERK1/2 phosphorylation in either of the cell lines. These data show that TKI258 moderately affect breast cancer survival by a mechanism that does not involve dephosphorylation of ERK1/2 and that does not allow stromal cells to interfere.

A different outcome was obtained with RAD001. At $2 \mu \mathrm{M}$, RAD001 reduced the viability of 2D-cultured MCF-7 cells by $\sim 20 \%$, but failed to affect the viability of $2 \mathrm{D}$-cultured MDA-MB-231 cells (Fig. 2). In homotypic spheriods, both cell lines were resistant to this drug. However, addition of stromal cells induced quite a different response. In the presence of hMSCs, RAD001 significantly reduced the viability of both breast cancer cell lines by $\sim 45 \%$. hCAFs had a similar effect on RAD001-treated MCF-7 cells, but were less effective on RAD001-treated MDA-MB-231 cells. Overall, total protein pattern in response to RAD001 were equivalent to the viability pattern. In MCF-7 cells, the sensitizing effect of stromal cells on RAD001 response was accompanied by an increase in apoptosis as indicated by increased abundance of the PARP-1 25-kDa fragment (Fig. 3A). However, PARP-1 fragmentation was not enhanced in MDA-MB-231 cells under these conditions (Fig. 4A). These data show that the response 


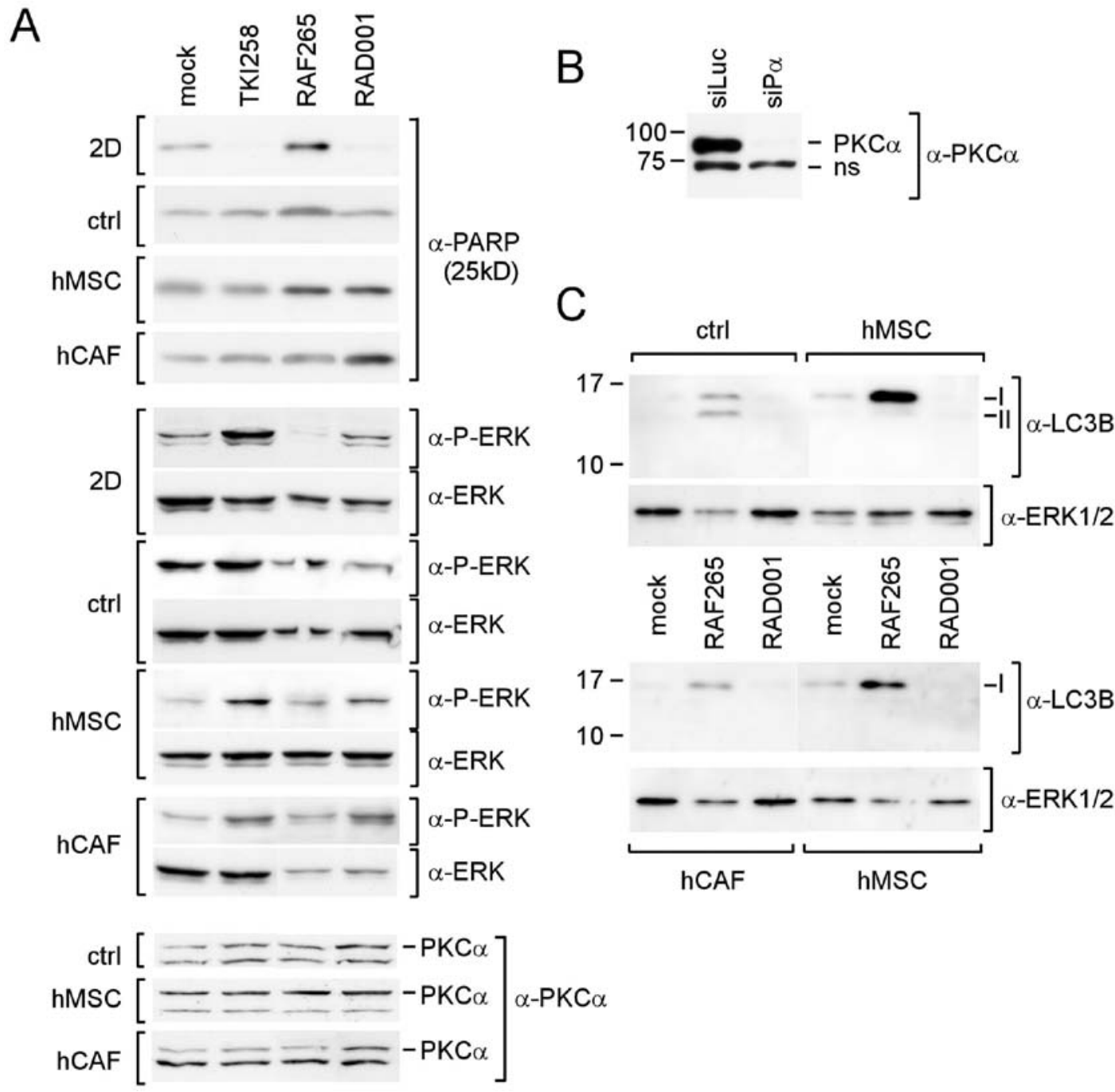

Figure 3. hMSCs and hCAFs cooperate with RAD001 to induce apoptosis of MCF-7 cells. (A) hMSCs and hCAFs cooperate with RAD001 to induce apoptosis of MCF-7 cells. MCF-7 homotypic or heterotypic spheroids were incubated with $10 \mu \mathrm{M}$ TKI258, $10 \mu \mathrm{M}$ RAF265 or $2 \mu \mathrm{M}$ RAD001 or mock-treated for 3 days and analyzed for expression of PARP1-25-kDa fragment, ERK1/2, phospho-ERK1/2 and PKC $\alpha$ by Western blot analysis. (B) The PKC $\alpha$ antibody specifically recognizes PKC $\alpha$ protein in MCF-7 protein extracts. MCF-7 cells were transfected with PKC $\alpha$-specific siRNA (siP $\alpha$ ) or control siRNA (siluc), grown in 3D cultures for 4 days and proteins analyzed by Western blot analysis using a PKCa-specific antibody. The data show that the upper of the two bands represents PKC $\alpha$ (ns, non-specific band). (C) RAF265-induced conversion of LC3B is inhibited by hMSCs and CAFs. MCF-7 homotypic or heterotypic spheroids were incubated with $10 \mu \mathrm{M}$ RAF265 or $2 \mu \mathrm{M}$ RAD001 or mock-treated for 3 days and analyzed for conversion and expression of LC3B by Western blot analysis.

of 3D-cultured breast cancer cells to RAD001 can be modulated by hMSCs and hCAFs.

Responses to RAF265 were strikingly different between the two cell lines. Under most conditions, MCF-7 cells were less susceptible to RAF265 than MDA-MB-231 cells. In response to $2 \mu \mathrm{M}$ RAF265, viability of MCF-7 cells reduced by $12-26 \%$. At $10 \mu \mathrm{M}$ RAF265, viability declined to $\sim 40 \%$, except when cells were kept in monolayers where $88 \%$ loss in viability was observed. In the latter case, loss in viability was accompanied by an increase in apoptosis (Fig. 3A). Stromal cells failed to modulate the cytotoxic effect of RAF265 on MCF-7 cells (Fig. 2). Nevertheless, both hMSCs and hCAFs interferred with RAF265-induced autophagy. In the absence of stromal cells, RAF265 induced autophagy in MCF-7 cells as indicated by the conversion of LC3B from its isoform I to isoform II (Fig. 3C). However, in the presence of hMSCs or hCAFs, LC3B isoform II could not be detected suggesting that LC3B conversion, and hence autophagy, was inhibited by these stromal cells. Of note, hMSCs increased the expression of LC3B isoform I. Since RAF265 targets RAF which regulates ERK1/2 phosphorylation through MEK1, RAF265 is expected to decrease the level of ERK1/2 phosphorylation. In accordance with this assumption, a strong decline in ERK1/2 phosphorylation was observed in 2D-cultured RAF265-treated MCF-7 cells (Fig. 3A). However, RAF265 failed to reduce ERK1/2 phosphorylation in 3D-cultured cells implying that MCF-7 cells react differently to RAF265 in 2D vs. 3D cultures.

RAF265 at 2 and $10 \mu \mathrm{M}$ was similarly effective on MDA-MB-231 cells. At either concentration, RAF265 reduced viability of MDA-MB-231 cells in monolayers by $\sim 30 \%$ and cells in homotypic aggregates by $\sim 60 \%$ (Fig. 2). In contrast to MCF-7 cells, MDA-MB-231 cells reacted on stromal cells in the presence of RAF265. In heterotypic aggregates containing 

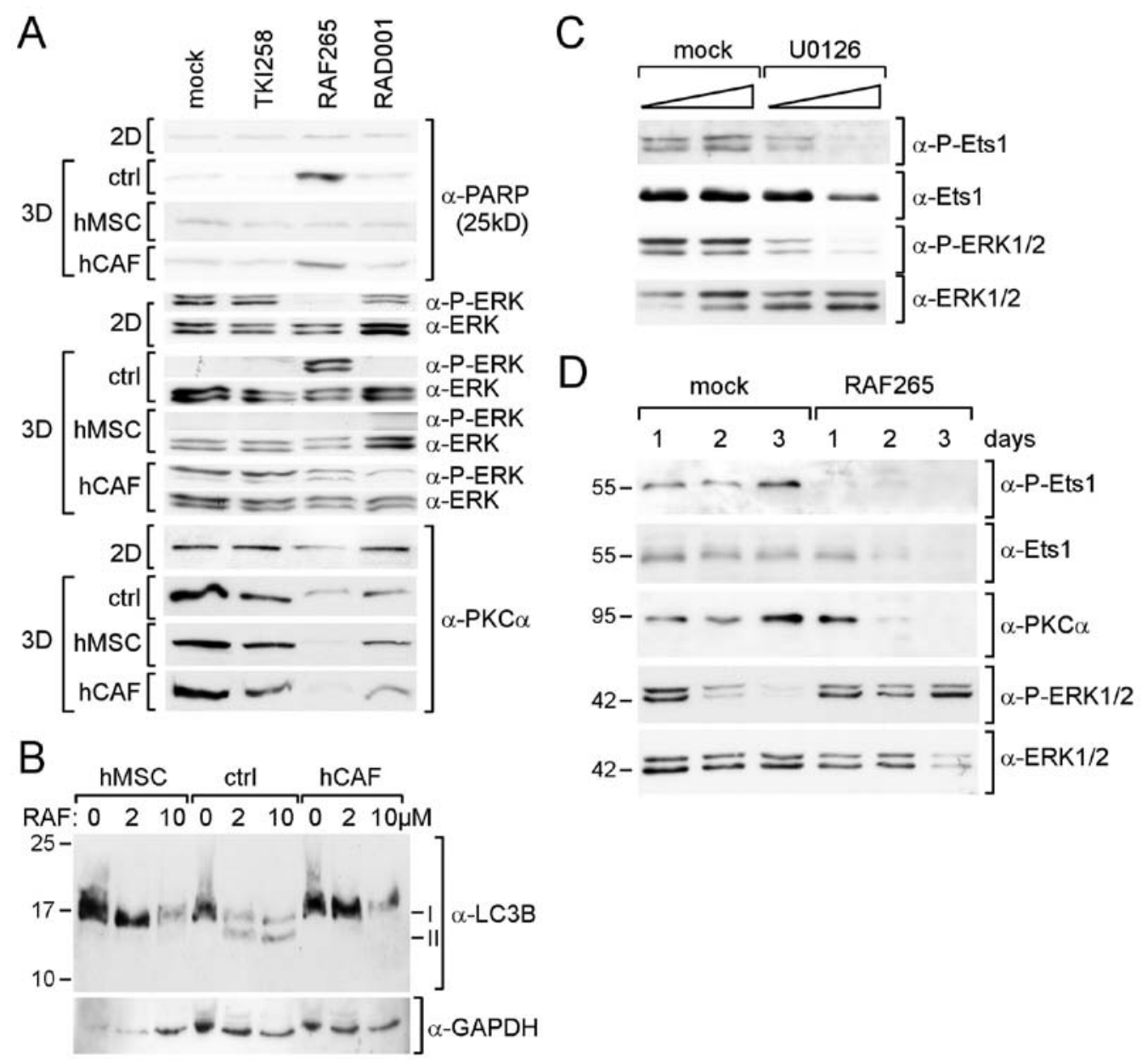

Figure 4. hMSCs and hCAFs support RAF265-induced downregulation of PKC $\alpha$ expression. (A) Three-day-old 3D-aggregates or 2D-monolayers of MDAMB-231 cells were incubated with $10 \mu \mathrm{M}$ TKI258, $10 \mu \mathrm{M}$ RAF265 or $2 \mu \mathrm{M}$ RAD001 or mock-treated in the presence or absence of stromal cells as indicated. After 3 days, proteins were extracted and analyzed for the abundance of phospho-ERK1/2, ERK1/2, PKC $\alpha$ and for the 25-kDa fragment of PARP-1 by Western blot analysis. (B) RAF265 induces autophagy. After homotypic or heterotypic MDA-MB-231 cell aggregates were incubated with RAF265 or mock-treated for three days, cells were lysed and proteins analyzed for LC3B conversion by Western blot analysis. (C) Ets1 is a substrate for ERK1/2 in MDA-MB-231 cells. Plastic-adherent MDA-MB-231 cells were incubated with 1 or $10 \mu \mathrm{M}$ MEK1 inhibitor U0126 or mock-treated o/n. Ets1 and ERK1/2 phosphorylation were examined by Western blot analysis. (D) In spite of its stimulatory effect on ERK1/2 activity, RAF265 blocks Ets1 phosphorylation and also induces a reduction in Ets1 and PKC $\alpha$ expression. Trypsinized MDA-MB-231 cells were transferred to 3D culture flasks and grown for 1, 2 or 3 days in the presence or absence of $2 \mu \mathrm{M}$ RAF265. Proteins were isolated and subjected to Western blot analysis by using antibodies against phospho-Thr38-Ets1, Ets1, PKC $\alpha$, phospho-ERK1/2 and ERK1/2.

hMSCs, viability of MDA-MB-231 cells dropped by $90-96 \%$, in those harboring hCAFs, viability losses ranged from 78 to $84 \%$. Changes in viability by stromal cells were statistically significant. Interestingly, while RAF265 induced strong PARP-1 fragmentation in homotypic aggregates, less fragmentation was observed in heterotypic aggregates (Fig. 4A) suggesting that apoptotic cell death is unlikely to be responsible for the cell loss as induced by stromal cells. Nor is autophagy likely to be involved in this effect since stromal cells inhibited conversion of LC3B (Fig. 4B). The latter finding is consistent with the data obtained with MCF-7 cells (Fig. 3C). However, in contrast to MCF-7 cells, MDA-MB-231 cells also reduced total LC3B expression in response to hMSCs and hCAFs in the presence of $10 \mu \mathrm{M}$ RAF265.

Analysis of the ERK1/2 status in RAF265-treated MDA-MB-231 cells revealed similarities with MCF-7 cells treated with this drug. Like MCF-7 cells, MDA-MB-231 cells responded to RAF265 by downregulating ERK1/2 phosphorylation if kept in monolayers, but not if cultured in
3D (Fig. 4A). In 3D cultures, RAF265-treated MDA-MB-231 cells showed even increased ERK1/2 phosphorylation. Further analysis revealed that switching from $2 \mathrm{D}$ to $3 \mathrm{D}$ culture conditions induced a gradual decline in ERK1/2 phosphorylation in MDA-MB-231 cells (Fig. 4D). This decline was prevented by RAF265. Higher ERK1/2 phosphorylation levels in 3D-cultured MDA-MB-231 cells as found in response to TGF $\beta$ (36) are linked to increased cell growth/survival in 3D (data not shown). Hence, increased ERK1/2 phosphorylation may help MDA-MB-231 cells to escape RAF265-induced cell death. Interestingly, the RAF265-induced increase in ERK1/2 phosphorylation was inhibited by hMSCs and hCAFs (Fig. 4A) suggesting that these stromal decreased viability in the presence of RAF265 by downregulating ERK1/2 phosphorylation.

A known substrate of ERK1/2 is the transcription factor Ets1 (39). Ets1 is involved in tumor progression (40), increases chemoresistance (41) and is highly expressed in MDA-MB-231 cells (42). To confirm that, also in MDA-MB-231 cells, phosphorylation of Ets1 at threonine-38 depends on ERK1/2, cells 


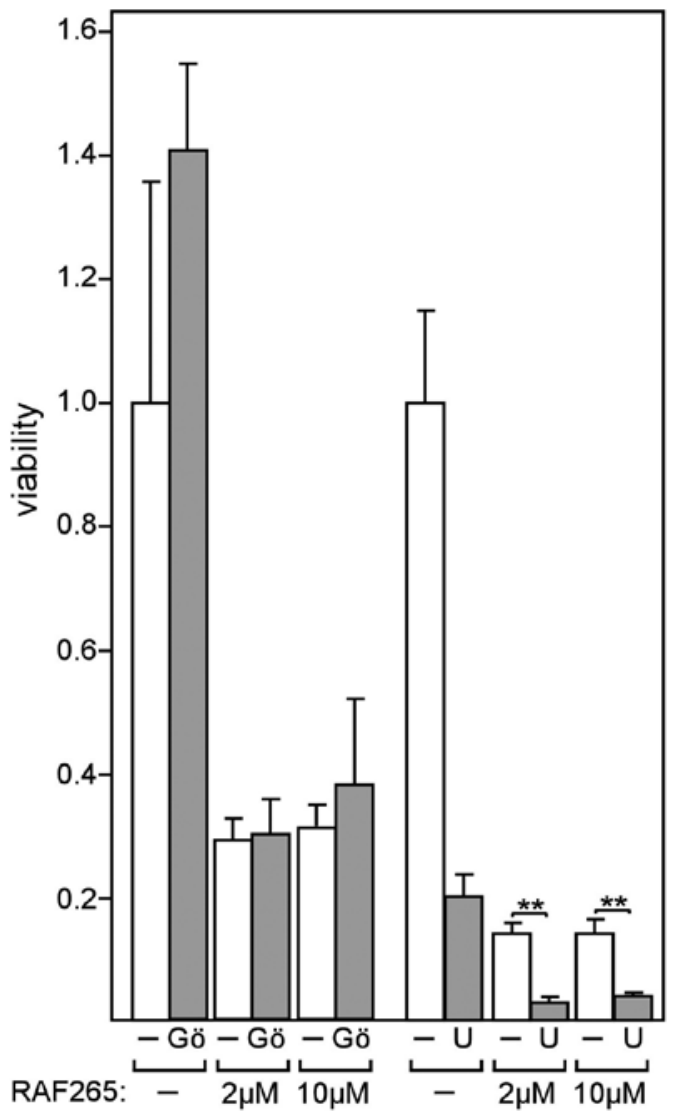

Figure 5. RAF265 cooperates with U0126, but not with Gö6976, to reduce survival of MDA-MB-231 cells. MDA-MB-231 cells in 3D-aggregates were incubated with RAF265, U0126 (U, $10 \mu \mathrm{M})$ and/or Gö6976 (Gö, $1 \mu \mathrm{M})$ or mock-treated as indicated for 3 days and analyzed for viability. Each bar represents the average value $( \pm$ SD) of 10 independent experiments. Statistical significance was determined by the student t-test $(* \mathrm{p}<0.001)$.

in monolayers were treated with MEK1 inhibitor U0126 and Ets1 phosphorylation was examined by Western blot analysis using a phospho-Thr-38-Ets-specific antibody. As expected, U0126 inhibited Ets1 phosphorylation along with ERK1/2 phosphorylation (Fig. 4C). We next examined how Ets1 phosphorylation is changed in 3D-cultured MDA-MB-231 cells in the presence and absence of RAF265. Surprisingly, Ets1 phosphorylation did not follow the pattern of ERK1/2 phosphorylation and was found to be constantly high in the absence and completely inhibited in the presence of RAF265 (Fig. 4D). This suggests that Ets1 phosphorylation is differently regulated in 3D- vs. 2D-cultured MDA-MB-231 cells. When we analyzed total Ets1 protein expression we noticed that the Ets1 protein levels was strongly downregulated in the presence, but not in the absence of RAF265 (Fig. 4D). In parallel, protein expression of $\mathrm{PKC} \alpha$ (protein kinase $\mathrm{C} \alpha$ ), a main regulator of Ets1 in cancer cells (38) ceased. The RAF265-induced decline in $\mathrm{PKC} \alpha$ was of interest, since we previously found that knock-down of PKC $\alpha$ reduces anchorage-independent growth of MDA-MB-231 cells (38). Comparing PKC $\alpha$ expression in RAF265-treated MDA-MB-231 cells in the presence and absence of stromal cells revealed that hMSCs and hCAFs further reduced PKC $\alpha$ expression levels (Fig. 4A). In contrast to MDA-MB-231 cells, MCF-7 cells did not change expression in response to RAF265 (Fig. 3A). Nor was PKC $\alpha$ expression altered in response to hMSCs or hCAFs.

Collectively, these data show that hMSCs and hCAFs have at least three effects on RAF265-treated MDA-MB-231 cells, they induce a further loss in cell viability and a further reduction in PKC $\alpha$ expression and they block RAF265-induced increase in ERK1/2 phosphorylation.

Inhibition of ERK1/2 phosphorylation sensitizes breast cancer cells to RAF265 in $3 D$ cultures. Downregulation of PKC $\alpha$ and inhibition of RAF265-induced ERK1/2 phosphorylation may have contributed to the sensitizing effect of hMSCs and hCAFs on 3D-cultured MDA-MB-231 cells to RAF265. To test this possibility we mimicked the effect of stromal cells on PKC $\alpha$ by PKC $\alpha$ inhibitor Gö6976 and on ERK1/2 phosphorylation by MEK1 inhibitor U0126. The latter had been shown to be effective to downregulate ERK1/2 phosphorylation also in 3D-cultured MDA-MB-231 cells (36). We found that Gö6976 had neither an effect on cell viability when given alone nor when added in combination with RAF265 (Fig. 5). In contrast, U0126 alone reduced cell viability almost as strongly as RAF265 and together with RAF265 induced viability losses comparable to those obtained with hMSCs (compare Fig. 5 with Fig. 2). This suggest that: i) ERK1/2 phosphorylation is critical for survival of MDA-MB-231 cells in 3D cultures and that ii) inhibition of RAF265-increased ERK1/2 phosphorylation is responsible for the effect of stromal cells on RAF265-treated MDA-MB-231 cells.

\section{Discussion}

hMSCs have been shown to affect breast cancer progression (5). Among the effects as exerted by these stromal cells are the interference with E-cadherin-dependent cell-cell contacts and, subsequently, with cell migration $(15,43)$. MSCs secrete a plethora of chemokines and cytokines (44) that may mediate the effects of these cells on tumor cells. Both changes in cellcell interactions and cytokines, such as interleukin-6 (IL-6), have been found to alter drug responses of tumor cells $(20,45)$. In particular, IL-6 has been reported to be responsible for the apoptosis-protecting effect of MSCs on neutrophils (46). Here we show that hMSCs are able to render breast cancer cells in 3D culture more susceptible to kinase inhibitors, namely mTOR inhibitor RAD001 and RAF inhibitor RAF265. The sensitizing effect on the response to RAD001 was similar with MCF-7 and MDA-MB-231 cells, although these cell lines belong to quite different breast cancer subtypes, MCF-7 to the luminal A (epithelial) subtype and MDA-MB-231 to the claudin-low (mesenchymal) subtype (47). This implies that the $\mathrm{PI} 3 \mathrm{~K} / \mathrm{AKT} / \mathrm{mTOR}$ pathway is functioning in a similar way in both cell lines, although MCF-7, but not MDA-MB-231 cells display an oncogenic mutation in PI3KCA (48). Inhibition of mTOR by rapamycin has been shown to downregulate the expression of PHLPP (PH domain and leucine rich repeat protein phosphatase), a phosphatase that inhibits AKT, subsequently leading to increased activation of the AKT/mTOR pathway (49). This feedback loop does not involve PI3K and is therefore likely not to be affected by PI3K mutations as that found in MCF-7 cells. Downregulation of PHLPP in response to mTOR inhibition has also been demonstrated with 
MDA-MB-231 cells (49). It is possible that hMSCs sensitized breast cancer cells to RAD001 by inhibiting downregulation of PHLPP.

Unlike the response to RAD001, the response to RAF265 was altered by hMSCs in MDA-MB-231 cells, but not in MCF-7 cells. Differences in the RAS/RAF/MEK1/ERK1/2 pathway may explain this discrepancy. MDA-MB-231, but not MCF-7 cells show oncogenic mutations in K-Ras and B-RAF (48). Mutations in B-RAF have been reported to render tumor cells more susceptible to RAF inhibitors in the presence of wild-type RAS $(50,51)$. Conversely, cells were more resistant to RAF inhibitors when wild-type-RAF and oncogenic RAS were present (52). This was accompanied by increased levels of ERK1/2 phosphorylation induced by a mechanism that involves C-RAF. Restoration of high ERK1/2 activities allows tumor cells to escape treatment with RAF265 inhibitors (53). In 3D cultures, the surviving RAF265-treated MDA-MB231 cells also showed increased ERK1/2 phosphorylation suggesting that MDA-MB-231 cells are capable of escaping RAF inhibition as well. This increase in ERK1/2 activity was prevented in the presence of hMSCs and, along with it, viability further declined. A similar effect on viability could be observed when MDA-MB-231 cells were treated with a combination of RAF265 and the MEK1/2 inhibitor U0126 to directly block recovery of ERK $1 / 2$ phosphorylation. Hence, it is likely that hMSCs supported the cytotoxic effect of RAF265 by preventing the rise of ERK1/2 phosphorylation. It should be noted that RAF265 not only inhibits B-RAF, but also VEGF receptor 2 (VEGFR2), and at higher concentrations, c-kit, PDGF receptor $\beta$ and RET. VEGFR2 is expressed in MDA-MB-231 cells (54) along with VEGF-C (55) allowing a VEGFR-2/VEGF-C positive feedback loop to be established which may promote cancer growth. VEGFR-2/3 inhibitor E7080 has been demonstrated to reduce growth of MDA-MB231 xenografts in mice (55). On the other hand, TKI258 inhibits VEGFR-2 to a similar extent as RAF265, but yet had almost no effect on survival of MDA-MB-231 cells.

Like MSCs, also carcinoma-associated fibroblasts have many effects on tumor progression, e.g., CAFs are capable of altering the gene expression profile of breast cancer cells (56). Moreover, a study on primary estrogen receptor-negative breast cancer specimens revealed that a 50-gene signature of the tumor stromal compartment, which also contains CAFs, predicts the sensitivity of the cancer to neoadjuvant chemotherapy (57) suggesting a link between stromal cells (CAFs) and drug response. Intriguingly, MSCs can differentiate to CAFs (17) which prompted us to analyze the effects of CAFs on the responses to kinase inhibitors as well. Some of the sensitizing activites on drug response as observed with hMSCs were also found with hCAFs, as hCAFs were able to mimic the effect of hMSCs on RAD001-treated MCF-7 cells and on RAF265treated MDA-MB-231 cells. Another feature that these two stromal cell types shared was the ability to inhibit LC3B conversion and, hence, autophagy, as induced by RAF265 in both MCF-7 and MDA-MB-231 cells. In conclusion, hMSCs and hCAFs show similarities in their activities on drug-treated breast cancer cells. Mechanistically, hMSCs and hCAFs may interact with breast cancer cells by cell-cell contact in a similar way and/or secrete the same cytokines/chemokines that are able to modify the efficacy of drugs.

\section{Acknowlegements}

This work was supported by the Deutsche Krebshilfe grant no. 109271 and by Novartis Pharma GmbH.

\section{References}

1. Tlsty TD and Coussens LM: Tumor stroma and regulation of cancer development. Annu Rev Pathol 1: 119-150, 2006.

2. Kim JB, Stein R and O'Hare MJ: Tumour-stromal interactions in breast cancer: the role of stroma in tumourigenesis. Tumour Biol 26: 173-185, 2005.

3. Wiseman BS and Werb Z: Stromal effects on mammary gland development and breast cancer. Science 296: 1046-1049, 2002.

4. Mueller MM and Fusenig NE: Friends or foes - bipolar effects of the tumour stroma in cancer. Nat Rev Cancer 4: 839-849, 2004.

5. Dittmer J: Mesenchymal stem cells and their role in tumor progression. In: Cancer Stem Cells. Jordan ME (ed). Nova Publisher, New York, NY, pp61-75, 2010.

6. Kidd S, Spaeth E, Klopp A, Andreeff M, Hall B and Marini FC: The (in) auspicious role of mesenchymal stromal cells in cancer: be it friend or foe. Cytotherapy 10: 657-667, 2008.

7. Yen L and Yen M-L: Mesenchymal stem cells and cancer - for better or for worse? J Cancer Molecules 4: 5-9, 2008.

8. Dominici M, Le Blanc K, Mueller I, Slaper-Cortenbach I, Marini F, Krause D, Deans R, Keating A, Prockop D and Horwitz E: Minimal criteria for defining multipotent mesenchymal stromal cells. The International Society for Cellular Therapy position statement. Cytotherapy 8: 315-317, 2006.

9. Uccelli A, Moretta L and Pistoia V: Mesenchymal stem cells in health and disease. Nat Rev Immunol 8: 726-736, 2008.

10. Mei SH, Haitsma JJ, Dos Santos CC, Deng Y, Lai PF, Slutsky AS, Liles WC and Stewart DJ: Mesenchymal stem cells reduce inflammation while enhancing bacterial clearance and improving survival in sepsis. Am J Respir Crit Care Med 182: 1047-1057, 2010.

11. Rojas M, Xu J, Woods CR, Mora AL, Spears W, Roman J and Brigham KL: Bone marrow-derived mesenchymal stem cells in repair of the injured lung. Am J Respir Cell Mol Biol 33: 145-152, 2005.

12. Nakamizo A, Marini F, Amano T, Khan A, Studeny M, Gumin J, Chen J, Hentschel S, Vecil G, Dembinski J, Andreeff $M$ and Lang FF: Human bone marrow-derived mesenchymal stem cells in the treatment of gliomas. Cancer Res 65: 3307-3318, 2005.

13. Studeny M, Marini FC, Champlin RE, Zompetta C, Fidler IJ and Andreeff M: Bone marrow-derived mesenchymal stem cells as vehicles for interferon-beta delivery into tumors. Cancer Res 62: 3603-3608, 2002.

14. Karnoub AE, Dash AB, Vo AP, Sullivan A, Brooks MW, Bell GW, Richardson AL, Polyak K, Tubo R and Weinberg RA: Mesenchymal stem cells within tumour stroma promote breast cancer metastasis. Nature 449: 557-563, 2007.

15. Dittmer A, Hohlfeld K, Lutzkendorf J, Muller LP and Dittmer J: Human mesenchymal stem cells induce E-cadherin degradation in breast carcinoma spheroids by activating ADAM10. Cell Mol Life Sci 66: 3053-3065, 2009.

16. Mishra PJ, Humeniuk R, Medina DJ, Alexe G, Mesirov JP, Ganesan S, Glod JW and Banerjee D: Carcinoma-associated fibroblast-like differentiation of human mesenchymal stem cells. Cancer Res 68: 4331-4339, 2008.

17. Spaeth EL, Dembinski JL, Sasser AK, Watson K, Klopp A, Hall B, Andreeff M and Marini F: Mesenchymal stem cell transition to tumor-associated fibroblasts contributes to fibrovascular network expansion and tumor progression. PLoS One 4: e4992, 2009.

18. Crawford Y, Kasman I, Yu L, Zhong C, Wu X, Modrusan Z, Kaminker $\mathrm{J}$ and Ferrara N: PDGF-C mediates the angiogenic and tumorigenic properties of fibroblasts associated with tumors refractory to anti-VEGF treatment. Cancer Cell 15: 21-34, 2009.

19. Medici D, Shore EM, Lounev VY, Kaplan FS, Kalluri R and Olsen BR: Conversion of vascular endothelial cells into multipotent stem-like cells. Nat Med 16: 1400-1406, 2010.

20. Gilbert LA and Hemann MT: DNA damage-mediated induction of a chemoresistant niche. Cell 143: 355-366, 2010.

21. Lemmon MA and Schlessinger J: Cell signaling by receptor tyrosine kinases. Cell 141: 1117-1134, 2010. 
22. Prat A and Perou CM: Mammary development meets cancer genomics. Nat Med 15: 842-844, 2009.

23. Charafe-Jauffret E, Ginestier C, Monville F, Finetti P, Adelaide J, Cervera N, Fekairi S, Xerri L, Jacquemier J, Birnbaum D and Bertucci F: Gene expression profiling of breast cell lines identifies potential new basal markers. Oncogene 25: 2273-2284, 2006.

24. Hollestelle A, Nagel JH, Smid M, Lam S, Elstrodt F, Wasielewski M, Ng SS, French PJ, Peeters JK, Rozendaal MJ, Riaz M, Koopman DG, Ten Hagen TL, De Leeuw BH, Zwarthoff EC, Teunisse A, van der Spek PJ, Klijn JG, Dinjens WN, Ethier SP, Clevers H, Jochemsen AG, den Bakker MA, Foekens JA, Martens JW and Schutte M: Distinct gene mutation profiles among luminal-type and basal-type breast cancer cell lines. Breast Cancer Res Treat 121: 53-64, 2009.

25. Yarden $\mathrm{Y}$ and Sliwkowski MX: Untangling the ErbB signalling network. Nat Rev Mol Cell Biol 2: 127-137, 2001.

26. Dey JH, Bianchi F, Voshol J, Bonenfant D, Oakeley EJ and Hynes NE: Targeting fibroblast growth factor receptors blocks PI3K/AKT signaling, induces apoptosis, and impairs mammary tumor outgrowth and metastasis. Cancer Res 70: 4151-4162, 2010.

27. Moreira C and Kaklamani V: Lapatinib and breast cancer: current indications and outlook for the future. Expert Rev Anticancer Ther 10: 1171-1182, 2010.

28. Di Cosimo S and Baselga J: Targeted therapies in breast cancer: where are we now? Eur J Cancer 44: 2781-2790, 2008.

29. Georgakis GV and Younes A: From Rapa Nui to rapamycin: targeting PI3K/Akt/mTOR for cancer therapy. Expert Rev Anticancer Ther 6: 131-140, 2006.

30. Zitzmann K, Ruden J, Brand S, Goke B, Lichtl J, Spottl G and Auernhammer CJ: Compensatory activation of Akt in response to mTOR and Raf inhibitors - a rationale for dual-targeted therapy approaches in neuroendocrine tumor disease. Cancer Lett 295: 100-109, 2010.

31. Mordant P, Loriot Y, Leteur C, Calderaro J, Bourhis J, Wislez M, Soria JC and Deutsch E: Dependence on phosphoinositide 3-kinase and RAS-RAF pathways drive the activity of RAF265, a novel RAF/VEGFR2 inhibitor, and RAD001 (Everolimus) in combination. Mol Cancer Ther 9: 358-368, 2010

32. Mirzoeva OK, Das D, Heiser LM, Bhattacharya S, Siwak D, Gendelman R, Bayani N, Wang NJ, Neve RM, Guan Y, Hu Z, Knight Z, Feiler HS, Gascard P, Parvin B, Spellman PT, Shokat KM, Wyrobek AJ, Bissell MJ, McCormick F, Kuo WL, Mills GB, Gray JW and Korn WM: Basal subtype and MAPK/ ERK kinase (MEK)-phosphoinositide 3-kinase feedback signaling determine susceptibility of breast cancer cells to MEK inhibition. Cancer Res 69: 565-572, 2009.

33. Junttila TT, Akita RW, Parsons K, Fields C, Lewis Phillips GD, Friedman LS, Sampath D and Sliwkowski MX: Ligandindependent HER2/HER3/PI3K complex is disrupted by trastuzumab and is effectively inhibited by the PI3K inhibitor GDC-0941. Cancer Cell 15: 429-440, 2009.

34. Pampaloni F, Reynaud EG and Stelzer EH: The third dimension bridges the gap between cell culture and live tissue Nat Rev Mol Cell Biol 8: 839-845, 2007.

35. Martens JW, Sieuwerts AM, Bolt-deVries J, Bosma PT, Swiggers SJ, Klijn JG and Foekens JA: Aging of stromal-derived human breast fibroblasts might contribute to breast cancer progression. Thromb Haemost 89: 393-404, 2003.

36. Dittmer A, Schunke D and Dittmer J: PTHrP promotes homotypic aggregation of breast cancer cells in three-dimensional cultures. Cancer Lett 260: 56-61, 2008.

37. Dittmer A, Vetter M, Schunke D, Span PN, Sweep F, Thomssen C and Dittmer J: Parathyroid hormone-related protein regulates tumor-relevant genes in breast cancer cells. J Biol Chem 281: 14563-14572, 2006.

38. Vetter M, Blumenthal SG, Lindemann RK, Manns J, Wesselborg S, Thomssen C and Dittmer J: Ets1 is an effector of protein kinase Calpha in cancer cells. Oncogene 24: 650-661, 2005.

39. Yang BS, Hauser CA, Henkel G, Colman MS, van Beveren C, Stacey KJ, Hume DA, Maki RA and Ostrowski MC: Ras-mediated phosphorylation of a conserved threonine residue enhances the transactivation activities of c-Ets1 and c-Ets2. Mol Cell Biol 16: 538-547, 1996.
40. Dittmer J: The biology of the Ets1 proto-oncogene. Mol Cancer 2: 29,2003

41. Kars MD, Iseri OD and Gunduz U: Drug resistant breast cancer cells overexpress ETS1 gene. Biomed Pharmacother 64: 458-462, 2010.

42. Lindemann RK, Braig M, Ballschmieter P, Guise TA, Nordheim A and Dittmer J: Protein kinase Calpha regulates Ets1 transcriptional activity in invasive breast cancer cells. Int J Oncol 22: 799-805, 2003

43. Klopp AH,Lacerda L, Gupta A,Debeb BG, Solley T, Li L, Spaeth E, $\mathrm{Xu}$ W, Zhang X, Lewis MT, Reuben JM, Krishnamurthy S, Ferrari M, Gaspar R, Buchholz TA, Cristofanilli M, Marini F, Andreeff $M$ and Woodward WA: Mesenchymal stem cells promote mammosphere formation and decrease E-cadherin in normal and malignant breast cells. PLoS 5: e12180, 2010.

44. Parekkadan B, van Poll D, Suganuma K, Carter EA, Berthiaume F, Tilles AW and Yarmush ML: Mesenchymal stem cell-derived molecules reverse fulminant hepatic failure. PLoS One 2: e941, 2007.

45. Hazlehurst LA and Dalton WS: Mechanisms associated with cell adhesion mediated drug resistance (CAM-DR) in hematopoietic malignancies. Cancer Metastasis Rev 20: 43-50, 2001.

46. Raffaghello L, Bianchi G, Bertolotto M, Montecucco F, Busca A Dallegri F, Ottonello L and Pistoia V: Human mesenchymal stem cells inhibit neutrophil apoptosis: a model for neutrophil preservation in the bone marrow niche. Stem Cells 26: 151-162, 2008.

47. Prat A and Perou CM: Deconstructing the molecular portraits of breast cancer. Mol Oncol 5: 5-23, 2011.

48. Hollestelle A, Elstrodt F, Nagel JH, Kallemeijn WW and Schutte M: Phosphatidylinositol-3-OH kinase or RAS pathway mutations in human breast cancer cell lines. Mol Cancer Res 5: 195-201, 2007.

49. Liu J, Stevens PD and Gao T: mTOR-dependent regulation of PHLPP expression controls the rapamycin sensitivity in cancer cells. J Biol Chem 286: 6510-6520, 2011.

50. Poulikakos PI, Zhang C, Bollag G, Shokat KM and Rosen N: RAF inhibitors transactivate RAF dimers and ERK signalling in cells with wild-type BRAF. Nature 464: 427-430, 2010.

51. Hatzivassiliou G, Song K, Yen I, Brandhuber BJ, Anderson DJ, Alvarado R, Ludlam MJ, Stokoe D, Gloor SL, Vigers G, Morales T, Aliagas I, Liu B, Sideris S, Hoeflich KP, Jaiswal BS, Seshagiri S, Koeppen H, Belvin M, Friedman LS and Malek S: RAF inhibitors prime wild-type RAF to activate the MAPK pathway and enhance growth. Nature 464: 431-435, 2010.

52. Heidorn SJ, Milagre C, Whittaker S, Nourry A, NiculescuDuvas I, Dhomen N, Hussain J, Reis-Filho JS, Springer CJ, Pritchard C and Marais R: Kinase-dead BRAF and oncogenic RAS cooperate to drive tumor progression through CRAF. Cell 140: 209-221, 2010.

53. Paraiso KH, Fedorenko IV, Cantini LP, Munko AC, Hall M, Sondak VK, Messina JL, Flaherty KT and Smalley KS: Recovery of phospho-ERK activity allows melanoma cells to escape from BRAF inhibitor therapy. Br J Cancer 102: 1724-1730, 2010.

54. Timoshenko AV, Rastogi S and Lala PK: Migration-promoting role of VEGF-C and VEGF-C binding receptors in human breast cancer cells. Br J Cancer 97: 1090-1098, 2007.

55. Matsui J, Funahashi Y, Uenaka T, Watanabe T, Tsuruoka A and Asada M: Multi-kinase inhibitor E7080 suppresses lymph node and lung metastases of human mammary breast tumor MDA-MB-231 via inhibition of vascular endothelial growth factor-receptor (VEGF-R) 2 and VEGF-R3 kinase. Clin Cancer Res 14: 5459-5465, 2008.

56. Samoszuk M, Tan J and Chorn G: Clonogenic growth of human breast cancer cells co-cultured in direct contact with serumactivated fibroblasts. Breast Cancer Res 7: R274-R283, 2005.

57. Farmer P, Bonnefoi H, Anderle P, Cameron D, Wirapati P, Becette V, Andre S, Piccart M, Campone M, Brain E, Macgrogan G, Petit T, Jassem J, Bibeau F, Blot E, Bogaerts J, Aguet M, Bergh J, Iggo R and Delorenzi M: A stroma-related gene signature predicts resistance to neoadjuvant chemotherapy in breast cancer. Nat Med 15: 68-74, 2009. 